\title{
Strategi Fundraising Di Badan Amil Zakat \\ Daerah (Bazda) Kota Bekasi
}

\author{
Ayatulloh Humaini
}

\begin{abstract}
One of the major success factors of a Zakah Management Organization (Organisasi Pengelola Zakat/OPZ) - whether it is BAZIS or LAZIS - is its sincerity in carrying out fundraising. If $O P Z$ is active, both in planning and fundraising strategy, the existence of $O P Z$ will last long. Local Zakat Agency (Badan Amil Zakat Daerah/BAZDA) Bekasi is a one of OPZ that has been in progress and development, particularly in fundraising results. This success is inseparable from fundraising strategy that has been implemented by BAZDA Bekasi. The results of this research illustrated that in 2012 BAZDA Bekasi had arranged two strategies: First of all the core strategy, consisted of: zakat collection unit, special Ramadan events, charity boxes, and media campaign. Secondly, a specific strategy, included convenience donation, post-donation services, and programs of action.
\end{abstract}

Key words: strategi fundraising, BAZDA, strategi inti, dan strategi khusus.

\section{Pendahuluan}

Masalah tingginya kemiskinan dan lebarnya ketimpangan distribusi pendapatan masih menjadi salah satu pekerjaan rumah membangun ekonomi negeri ini, yang dari waktu ke waktu terus diupayakan untuk diatasi dan dikurangi. (Muhammad, 2007 : Viii) Zakat, infaq dan shadaqah merupakan salah satu potensi umat Islam yang dapat disumbangkan dalam pembangunan nasional, guna meningkatkan taraf hidup dan kesejahteraan masyarakat serta sebagai salah satu alternatif pemberantasan kemiskinan. (Departemen Agama RI, 1997 : iii)

Dengan jumlah penduduk islam terbanyak, maka potensi zakat di tanah air kita ini tergolong amat besar. Hanya saja sampai saat ini potensi zakat yang amat besar belum tergali dan teraktualisasikan secara optimal dan maksimal. Bahkan menurut data yang dikutip oleh Muchtar Zarkasyi pada tahun 2007 zakat mal baru terkumpul oleh BAZNAS baru sekitar Rp 800 milyar-an atau belum mencapai 10\% dari potensi yang ada. (Zarkasyi, $2008: 3$ )

Dalam data Direktorat Zakat, pemberdayaan zakat masih terkendala beberapa hal, seperti pemahaman yang sempit tentang zakat, dimana zakat hanya diasumsikan dengan zakat fitrah saja. Padahal nilai zakat fitrah terlalu kecil jika dibandingkan dengan nilai zakat mal. Justru zakat mal yang seharus dibebankan kepada para pemilik modal tidak tersentuh oleh kewajiban zakat. Selain itu, masih diperoleh data bahwa pola penyaluran zakat oleh masyarakat yang tidak melalui lembaga resmi. (Direktorat Pemberdayaan Zakat, 2008 : 9)

Keberhasilan zakat tergantung kepada pendayagunaan dan pemanfaatannya. Walaupun seorang wajib zakat (muzakki) mengetahui dan mampu memperkirakan jumlah zakat yang akan ia keluarkan, tidak dibenarkan ia menyerahkannya kepada sembarang orang yang ia sukai. Zakat harus diberikan kepada yang berhak (mustahiq) yang sudah ditentukan dengan agama. Penyerahan yang benar adalah melalui badan amil zakat. Walaupun 
demikian kepada badan amil zakat manapun tetap terpikul kewajiban untuk mengefektifkan pendayagunaannya. (Ibid : 29)

Umumnya badan amil zakat mempunyai tiga tugas pokok. Yakni mengumpulkan, mendistribusikan dan mendayagunakan. Tiga tugas pokok tersebut sekaligus distrukturkan menjadi tiga divisi utama, yaitu divisi pengumpulan (fundraising), divisi pengelolaan (keuangan) dan divisi pendayagunaan (penyaluran). (Direktorat Pemberdayaan Zakat, $2008: 56$ )

Fungsi dan tugas divisi fundraising memang bergerak dalam bidang pengumpulan dana zakat, infaq dan shadaqah dari masyarakat, dana ini tidak hanya berasal dari perorangan, melainkan juga dari berbagai perusahaan dan lembaga. Selanjutnya fundraising juga tidak hanya diartikan sebagai divisi pengumpul dana semata, tetapi juga terhadap bentuk partisipasi dan kepedulian dari setiap elemen masyarakat yang dapat dimanfaatkan untuk keperluan organisasi. Fundraising biasanya dilakukan oleh lembagalembaga atau organisasi nirlaba (Purwanto, 2009 : 11). Untuk menyampaikan amanah Allah ini, maka diperlukan suatu organisasi atau lembaga zakat yang di dalamnya terdapat pekerja-pekerja (amilin) yang diberi kewenangan untuk mengambil dana-dana zakat dari pada aghniya (muzakki) dan menyalurkannya kepada golongan yang berhak menerimanya (mustahik). Perintah Allah SWT untuk mengambil zakat terdapat dalam al-Qur`an Surah At-Taubah/09:103, yaitu:

"Ambillah zakat dari sebagian harta mereka, dengan zakat itu kamu membersihkan dan mensucikan mereka dan mendoalah untuk mereka. Sesungguhnya doa kamu itu (menjadi) ketenteraman jiwa bagi mereka. dan Allah Maha mendengar lagi Maha mengetahui."

Tanpa menampilkan fungsi dan peran divisi yang lain, sesungguhnya jatuh bangunnya suatu organisasi atau lembaga zakat terletak pada kreatifitas divisi pengumpulannya (divisi Fundraising). Boleh-boleh saja organisasi zakat memiliki struktur organisasi dan ditunjang dengan fasilitas lengkap, serta memiliki program pendayagunaan yang baik. Tetapi, semuanya itu tidak akan dapat bertahan lama atau tidak dapat terus berkembang apabila tidak didukung oleh divisi fundraising yang kreatif dan inovatif. Sekali lagi, sesungguhnya divisi fundraising merupakan inti dari organisasi atau lembaga zakat.

Keberhasilan sebuah organisasi pengelola zakat (OPZ), baik LAZIS maupun BAZIS tergantung dari keseriusannya dalam menjalankan aktifitas fundraising ini. Jika OPZ aktif dan baik dalam merencanakan bentuk pola dan strategi fundraising maka eksistensi OPZ akan berlangsung lama. Namun, apabila tidak mampu merencanakan dan membuat strategi dalam penggalian dana masyarakat, maka bisa dipastikan OPZ tersebut kekurangan dana, sehingga eksistensi lembaga tersebut dalam posisi terancam dan untuk menghidupkan kembali perlu suntikan dana yang besar (Purwanto, $2009: 5$ ).

Beberapa tahun terakhir ini memang lembaga-lembaga ataupun organisasi-organisasi pengelola zakat mulai banyak bermunculan, tidak hanya di Ibu Kota saja melainkan sampai ke setiap pelosok Kota dan Kabupaten di tanah air kita ini. Selain disebabkan karena memang potensi dana zakat yang sangat besar karena negara kita ini adalah negara dengan jumlah penduduk muslim terbanyak di dunia, juga karena adanya dukungan dari pemerintah yang mengeluarkan UU Tentang Zakat pada Tahun 1999. 
Lembaga-lembaga atau organisasi-organisasi pengelola zakat yang terus bertambah juga semakin berkembang, hampir disetiap jalan kita akan melihat iklan-iklan mengenai lembaga zakat dan bahkan sangat banyak juga kita temukan iklan-iklannya itu di berbagai media masa, seperti di televisi, radio, koran atau majalah. Dari sekian banyaknya lembaga dan organisasi yang ada di nusantara ini, penulis merasa tertarik dengan organisasi zakat yang sedang mulai besar dan dikenal namanya di Kota Bekasi, yaitu Badan Amil Zakat Daerah (BAZDA) Kota Bekasi. Karena selain sebagai organisasi zakat yang paling banyak memberikan manfaat terhadap warga kurang mampu di Kota Bekasi, BAZDA Kota Bekasi juga merupakan organisasi zakat yang sedang mengalami kemajuan dan perkembangan terutama dalam pengumpulan dana zakat. Peningkatan dana zakat yang terkumpul di BAZDA Kota Bekasi pad tabel berikut: data diperoleh dari Neraca Penerimaan Zakat, Infaq dan shadaqah BAZDA Kota Bekasi

Tabel

Penerimaan Zakat Profesi

\begin{tabular}{|c|c|c|}
\hline No. & Tahun & Jumlah Penerimaan Zakat Profesi \\
\hline 1 & 2009 & $767.823 .000,-$ \\
\hline 2 & 2010 & $1.286 .949 .000,-$ \\
\hline 3 & 2011 & $1.829 .160 .000,-$ \\
\hline
\end{tabular}

Tabel

Penerimaan Zakat, Infaq dan Shadaqah

\begin{tabular}{|c|c|r|}
\hline No & Tahun & Jumlah Penerimaan Zakat, Infaq dan Shodaqah \\
\hline 1 & 2009 & $2.784 .206 .000,-$ \\
\hline 2 & 2010 & $4.519 .137 .000,-$ \\
\hline 3 & 2011 & $6.049 .930 .500,-$ \\
\hline
\end{tabular}

Berdasarkan data tersebut terlihat selama tiga tahun terahir adanya kenaikan yang cukup signifikan, kenaikan dana zakat profesi yang diperoleh BAZDA Kota Bekasi dari tahun 2009 ke 2010 sebesar 67,7\% dan dari tahun 2010 ke 2011 juga berhasil meningkatkan pendapatan sebesar $42,2 \%$. Bukan hanya pendapatan dana zakat profesi saja yang mengalami peningkatan tetapi pendapatan dana zakat, infaq dan shadaqah (ZIS) juga berhasil ditingkatkan setiap tahunnya. Tercatat peningkatan pendapatan dana ZIS dari tahun 2009 ke 2010 sebesar 62,4\%, kemudian pada tahun berikutnya yaitu dari tahun 2010 ke 2011 perolehan dana ZIS di BAZDA Kota Bekasi meningkat sebesar 33,8\%. Melihat keberhasilan dalam pengumpulan dana ZIS tersebut, penulis tertarik untuk mengkaji lebih dalam mengenai strategi fundraising (Penggumpulan dana) yang ada di Badan Amil Zakat Daerah (BAZDA) Kota Bekasi. Penulis membatasi penelitian pada strategi fundraising BAZDA Kota Bekasi pada tahun 2011-2012

\section{Metodologi Penelitian}

Penelitian ini mengunakan pendekatan kualitatif. Pendekatan kualitatif adalah pendekatan yang mengacu pada prosedur penelitian yang menghasilkan penelitian deskriptif, 
seperti perkataan orang, dan prilaku yang dapat diamati. (Moleong, 2003 : 12). Peneliti menggunakan pendekatan kualitatif dalam melakukan penelitian karena berharap dengan mengunakan pendekatan kualitatif didapatkan hasil penelitian yang menyajikan data yang akurat dan digambarkan secara jelas dari kondisi sebenarnya mengenai strategi fundraising di Badan Amil Zakat Daerah (BAZDA) Kota Bekasi yang beralamat di Jalan Jenderal Ahmad Yani No. 11 Bekasi. Adapun waktu pelaksanaan penelitian ini dilakukan mulai bulan September 2012 sampai dengan Desember 2012 Teknik pemilihan informan dalam penelitian ini menggunakan teknik purposive sampling (bertujuan). Dimana sampel utama diwawancarai tanya-jawab dengan lisan dan langsung bertatap muka agar memperoleh data yang lebih akurat dengan pedoman wawancara. antara lain: Ketua BAZDA Kota Bekasi dan Kepala Divisi Fundraising BAZDA Kota Bekasi. Disamping itu, didukung data Observasi dan studi dokumen berkaitan dengan strategi fundraising di BAZDA Kota Bekasi.

\section{Definisi Strategi Fundraising Strategi}

Secara etimologi, strategi berasal dari kata Yunani Strategos yang berarti Jenderal. (Steiner dan Miller : 20) Strategi pada mulanya berasal dari peristiwa peperangan, yaitu sebagai suatu siasat untuk mengalahkan musuh. Namun pada akhirnya strategi berkembang untuk semua kegiatan organisasi termasuk keperluan ekonomi, sosial, budaya dan agama. (Rafi'udin danl Jalil, 1997 : 76).Dalam Kamus Istilah Manajemen, strategi adalah rencana yang cermat mengenai kegiatan untuk mencapai sasaran khusus dan saling berhubungan dalam hal, waktu dan ukuran. (Panitia Istilah Manajemen Lembaga PPM, 1983 : 245)

Sedangkan menurut Prof. Drs. Onong Uchyana Efendi, M.A., mengatakan: "Strategi pada hakikatnya adalah perencanaan (planning) dan manajemen untuk mencapai suatu tujuan, akan tetapi untuk mencapai tujuan tersebut, strategi tidak berfungsi sebagai peta jalan yang hanya memberikan arah saja, melainkan harus mampu menunjukan bagaimana taktik operasionalnya”. (Uchyana, 2002: 32)

\section{Fundraising}

Untuk memahami istilah fundraising kita bisa merujuk terlebih dahulu ke dalam kamus bahasa inggris. Fundraising diterjemahkan dengan pengumpulan uang. Fundraising tidak hanya mengumpulkan dana semata, tetapi juga segala bentuk partisipasi dan kepedulian yang diberikan masyarakat kepada organisasi atau lembaga yang berbentuk dana dan segala macam benda dan fasilitas yang dapat dimanfaatkan untuk keperluan dan kesesuaian dengan lembaga. (April Purwanto, 2009 : 11). Sedangkan istilah Fundraising pada konteks lebih khusus berkaitan dengan ZIS, yaitu suatu upaya atau proses kegiatan dalam rangka menghimpun dana Zakat, Infaq dan Shadaqah serta sumber daya lainnya dari masyarakat baik individu, kelompok organisasi dan perusahaan yang akan disalurkan dan didayagunakan untuk mustahik. (Departemen Agama RI, 2007: 66.)

\section{Profil Singkat BAZDA Kota Bekasi}

Badan Amil Zakat Daerah Kota Bekasi atau disingkat BAZDA Kota Bekasi adalah sebuah Badan yang bertugas mengumpulkan, mengelola dan mendistribusikan zakat. 
BAZDA Kota Bekasi sesuai misi yang diemban berusaha mewujudkan masyarakat Bekasi sadar zakat dan manfaat zakat. BAZDA Kota Bekasi dibentuk dan dikukuhkan berdasarkan: Keputusan Walikota Bekasi No. 451.12/Kep.291.Kesos/VIII/2008. BAZDA Kota Bekasi merupakan lembaga pemerintah nonstruktural yang bersifat mandiri dan bertanggungjawab dalam kegiatan pengelolaan zakat yang meliputi kegiatan pengumpulan, pendistribusian dan pendayagunaan zakat. Ketua pelaksana tahun 2012 yaitu H. Fuad Noor Yusuf. BAZDA. Kota Bekasi juga menjadi pusat koordinasi BAZ Kecamatan se-Kota Bekasi yang berjumlah 12 Kecamatan:BAZ Bekasi Timur BAZ Rawa Lumbu BAZ Bekasi Barat BAZ Pondok Melati BAZ Bekasi Selatan BAZ MustikajayaBAZ Pondok Gede BAZ Bantar Gebang BAZ Jatiasih BAZ Bekasi UtaraBAZ Medan Satria BAZ Jati Sampurna. (Profil BAZDA Kota Bekasi, 2012 : 2)

Selain itu BAZDA Kota Bekasi juga membentuk Unit Pengumpul Zakat (UPZ) tingkat Kelurahan se-Kota Bekasi yang berjumlah 56 UPZ Kelurahan Dokumentasi Data UPZ BAZDA Kota Bekasi, yaitu:

1. UPZ Kelurahan Jati Makmur

2. UPZ Kelurahan Jati Waringin

3. UPZ Kelurahan Jati Bening

4. UPZ Kelurahan Jati Cempaka

5. UPZ Kelurahan Jati Bening Baru

6. UPZ Kelurahan Jati Karya

7. UPZ Kelurahan Jati Sampurna

8. UPZ Kelurahan Jati Rangga

9. UPZ Kelurahan Jati Ranggon

10. UPZ Kelurahan Jati Raden

11. UPZ Kelurahan Jati Murni

12. UPZ Kelurahan Jati Melati

13. UPZ Kelurahan Jati Warna

14. UPZ Kelurahan Jati Rahayu

15. UPZ Kelurahan Jati Sari

16. UPZ Kelurahan Jati Luhur

17. UPZ Kelurahan Jati Rasa

18. UPZ Kelurahan Jatiasih

19. UPZ Kelurahan Jati Mekar

20. UPZ Kelurahan Jati Kramat

21. UPZ Kelurahan Ciketing Udik

22. UPZ Kelurahan Sumur Batu

23. UPZ Kelurahan Cikiwul

24. UPZ Kelurahan Bantar Gebang

25. UPZ Kelurahan Pedurenan

26. UPZ Kelurahan Cimuning

27. UPZ Kelurahan Mustika Jaya

28. UPZ Kelurahan Mustika Sari
29. UPZ Kelurahan Marga Hayu

30. UPZ Kelurahan Bekasi Jaya

31. UPZ Kelurahan Duren Jaya

32. UPZ Kelurahan Aren Jaya

33. UPZ Kelurahan Bojong Menteng

34. UPZ Kelurahan Sepanjang Jaya

35. UPZ Kelurahan Pengasinan

36. UPZ Kelurahan Jaka Mulya

37. UPZ Kelurahan Jaka Setia

38. UPZ Kelurahan Pekayon Jaya

39. UPZ Kelurahan Marga Jaya

40. UPZ Kelurahan Kayuringin Jaya

41. UPZ Kelurahan Bintara Jaya

42. UPZ Kelurahan Bintara

43. UPZ Kelurahan Kranji

44. UPZ Kelurahan Kota Baru

45. UPZ Kelurahan Jaka Sampurna

46. UPZ Kelurahan Harapan Mulya

47. UPZ Kelurahan Kali Baru

48. UPZ Kelurahan Medan Satria

49. UPZ Kelurahan Pejuang

50. UPZ Kelurahan Harapan Jaya

51. UPZ Kelurahan Kaliabangtengah

52. UPZ Kelurahan Perwira

53. UPZ Kelurahan Harapan Baru

54. UPZ Kelurahan Teluk Pucung

55. UPZ Kelurahan Marga Mulya

56. UPZ Kelurahan Rawa Lumbu 


\section{Program dan Kegiatan BAZDA Kota Bekasi 2012}

\begin{tabular}{|c|c|c|}
\hline NO & KETERANGAN & JUMLAH \\
\hline & I. FAKIR & \\
\hline \multirow[t]{2}{*}{1} & H-7 Fakir Miskin & $\mathrm{Rp} 3.000 .000 .000$ \\
\hline & II. MISKIN & \\
\hline \multirow[t]{4}{*}{2} & Beasiswa & \\
\hline & $\mathrm{MI}: 2.500 \times 12 \times 15.000$ & $\operatorname{Rp} 450.000 .000$ \\
\hline & MTs : $1.200 \times 12 \times 20.000$ & $\mathrm{Rp} 288.000 .000$ \\
\hline & MA : $1.200 \times 12 \times 25.000$ & Rp 360.000.000 \\
\hline 3 & Dana Kesehatan : 16 orang x 56 Kelurahan x 500.000 & $\operatorname{Rp} 448.000 .000$ \\
\hline 3 & Pengobatan Keliling Gratis & $\operatorname{Rp} 400.000 .000$ \\
\hline 5 & Yatim : 20 orang $\times 56$ Kelurahan $\times 150.000=$ & $\operatorname{Rp} 168.000 .000$ \\
\hline 6 & Dana Kematian : $10 \times 12 \times 500.000=$ & $\mathrm{Rp} 60.000 .000$ \\
\hline 7 & Dana Khitanan : $56 \times 500.000=$ & $\mathrm{Rp} 28.000 .000$ \\
\hline \multirow[t]{2}{*}{8} & Dana Bergulir & $\mathrm{Rp} 100.000 .000$ \\
\hline & III. FISABILILLAH & \\
\hline 9 & \multirow{2}{*}{$\begin{array}{l}\text { Sarana Ibadah : } 2 \text { x } 56 \text { Kelurahan x } 3.000 .000= \\
\text { Honor Guru Ngaji di Masjid: } 1 \text { x } 56 \text { Kelurahan x } 100.000 \\
\times 12=\end{array}$} & $\mathrm{Rp} 336.000 .000$ \\
\hline 10 & & Rp 67.200 .000 \\
\hline 11 & RA : $20 \times 12 \times 500.000=$ & $\mathrm{Rp} 120.000 .000$ \\
\hline 12 & DTA : 7 DTA $\times 12 \times 500.000=$ & Rp 42.000.000 \\
\hline 13 & Proposal & $\operatorname{Rp} 254.800 .000$ \\
\hline 14 & $\begin{array}{l}\text { Pengadaan Ambulan (Mobil Layanan Kesehatan } \\
\text { Masyarakat) }\end{array}$ & Rp 300.000.000 \\
\hline 15 & Penerbitan Buletin BAZDA : $5.000 .000 \times 12$ & $\mathrm{Rp} 60.000 .000$ \\
\hline 16 & Laporan Keuangan Melalui Media Cetak & Rp 50.000.000 \\
\hline \multirow[t]{2}{*}{17} & Operasional BAZDA & $\mathrm{Rp} 43.000 .000$ \\
\hline & IV. IBNU SABIL & \\
\hline \multirow[t]{2}{*}{18} & Ibnusabil : 300 Personal $\times 300.000=$ & $\operatorname{Rp} 90.000 .000$ \\
\hline & V. GHORIMIN & \\
\hline \multirow[t]{2}{*}{19} & Ghorimin & $\mathrm{Rp} 100.000 .000$ \\
\hline & VI. MU'ALAF & \\
\hline \multirow[t]{2}{*}{20} & Pembinaan Mu'alaf & $\operatorname{Rp} 25.000 .000$ \\
\hline & VII. RIQAB & \\
\hline 21 & Alokasi Kejadian Luar Biasa & $\operatorname{Rp} 10.000 .000$ \\
\hline \multicolumn{2}{|r|}{ VIII. AMILIN } & \\
\hline 22 & Biaya Operasional BAZDA Kota Bekasi (terlampir) & Rp 325.000.000 \\
\hline \multicolumn{2}{|r|}{ JUMLAH } & Rp 7.125.000.000 \\
\hline
\end{tabular}

\section{Pembahasan}

Berdasarkan hasil penelitian yang telah penulis lakukan di BAZDA Kota Bekasi, penulis dapat menerangkan bahwa strategi fundraising di BAZDA Kota Bekasi terdiri dari yaitu strategi utama dan strategi khusus. 


\section{Strategi Utama}

\section{a. Membentuk Unit Pengumpul Zakat (UPZ)}

Strategi pertama yang dilakukan oleh BAZDAKota Bekasi adalah strategi pembentukan UPZ di tiap-tiap Sekolah, Masjid, Perusahaan dan di kalangan Dinas (Instansi atau SKPD) se-Kota Bekasi. Akan tetapi, dari bebrapa golongan UPZ yang dimiliki oleh BAZDA Kota Bekasi ternyata hanya pada golongan UPZ Dinas saja yang sudah aktif dalam hal zakat profesi. Adapun untuk UPZ Madrasah, Masjid dan Perusahaan ini belum aktif mengenai pengumpulan zakat profesi, tetapi cukup aktif dalam hal pengumpulan zakat fitrah saja

Langkah-langkah yang dilakukan BAZDA Kota Bekasi dalam hal pembentukan UPZ adalah melakukan pendataan potensi zakat, infaq dan shadaqoh. Kemudian BAZDA melakukan sosialisasi Undang-undang No. 38 Tahun 1999 mengenai pengelolaan zakat, Perda No. 2 Tahun 2008, Perwal No. 20 Tahun 2009, Instruksi Walikota No. 1 tahun 2010 dan Fatwa MUI Kota Bekasi No. 36 Tahun 2009. Sosialisai ini dilakukan dengan cara melakukan kunjungan langsung ke Dinas se kota Bekasi tentang kewajiban menunaikan zakat 2,5\% kepada Pegawai Negeri Sipil (PNS) yang beragama Islam di lingkungan Pemerintah Kota Bekasi yang berpenghasilan dari gaji atau penghasilan lainnya minimal Rp. 1.600.000,-(satu juta enam ratus ribu rupiah) tiap bulan diwajibkan dan kepada pegawai yang berpenghasilan di bawah itu dianjurkan untuk mengeluarkan infaq, shadaqoh melalui UPZ yang telah dibentuk olah BAZDA di lingkungan kerja masing-masing Kantor Kementerian Agama Kota Bekasi, Himpunan Peraturan Daerah Kota Bekasi Tentang Pengelolaan Zakat, (BAZDA Kota Bekasi, 2011: 67).

Setelah dibentuknya UPZ di tiap-tiap dinas atau instansi dilingkungan Pemerintah Daerah Kota Bekasi maka secara otomatis pada setiap awal bulan BAZDA menerima setoran dari beberapa bendahara UPZ. kemudian setiap UPZ juga diberikan atau mendapat bagian amilin sebesar 2,5\% dari jumlah yang terkumpul oleh UPZ tersebut. (ibid)

Berdasarkan hasil wawancara, strategi membentuk UPZ ini adalah strategi yang paling efektif bagi BAZDA Kota Bekasi dalam mengumpulkan dana Zakat, Infaq dan Shadaqoh. Pernyataan tersebut sebagaimana dijelaskan oleh Bapak Suherman selaku kepala divisi fundraising BAZDA Kota Bekasi:“....Adapun strategi yang paling efektif diantara keempat itu eeem... biasanya pembentukan UPZ karna pemasukan rutin BAZDA tiap bulan ya itu adalah dari UPZ tersebut." (Wawancara Pribadi dengan Bapak Suherman, tanggal 14 November 2012). Selain itu, biaya yang diperlukan oleh BAZDA Kota Bekasi untuk membentuk UPZ Dinas/Instansi ini juga cukup sederhana, pihak BAZDA hanya memerlukan dana untuk penerbitan buku "Himpunan Peraturan Daerah Kota Bekasi Tentang Pengelolaan Zakat" dan biaya kunjungan atau sosialisasi ke tiap-tiap Dinas seKota Bekasi. Namun pendapatan yang bisa terkumpul dari UPZ ini cukup rutin setiap bulannya dan terbilang cukup besar. Mengenai nominal biaya yang dikeluarkan BAZDA Kota Bekasi untuk pembentukan UPZ Dinas se-Kota Bekasi ini tidak lebih dari Rp. 10.000.000 (Sepuluh Juta Rupiah), untuk jangka waktu SK kepengurusan selama tiga tahun. Selanjutnya diperlukan juga biaya untuk rapat koordinasi UPZ dan diperlukan dana untuk rapat koordinasi tersebut untuk dua kali pertemuan dalam setiap satu tahunnya kurang lebih sebesar Rp. 10.000.000. Adapun pendapatan rutin yang diterima BAZDA 
Kota Bekasi dari setoran UPZ Dinas bisa mencapai Rp. 150.000.000 sampai dengan 180.000.000 setiap bulannya.

\section{b. Special Event Ramadhan (Gerai Ramadhan)}

Pada saat bulan suci ramadhan BAZDA Kota Bekasi mengadakan program Gerai Ramadhan karena sudah sama-sama kita ketahui bahwa bulan ramadhan adalah bulan zakat dan shadaqoh karena selain pada bulan ini umat Islam diwajibkan untuk menunaikan zakat fitrah juga pada bulan ini umat islam banyak mengeluarkan shadaqoh. Untuk itu BAZDA Kota Bekasi juga tidak mau menyia-nyiakan moment bulan ramadhan ini untuk melakukan strategi jamput bola yakni dengan membuka Gerai Ramadhan di tempat-tempat yang banyak dikunjungi seperti di pusat pembelanjaan dan restauran atau rumah makan populer di Kota Bekasi.

Secara umum Program Gerai Ramadhan ini memiliki tiga tujuan utama yaitu: Pertama, untuk memotivasi dan memberikan kemudahan bagi para muzakki yang ingin menyalurkan zakat, infaq dan shadaqohnya. Kedua, untuk lebih mempublikasikan BAZDA Kota Bekasi. Ketiga, untuk memaksimalkan pengumpulan dana ZIS dari warga Kota Bekasi.

Adapun proses pelaksanaan program gerai ramadhan ini diawali dengan mengirimkan proposal penawaran kerjasama, yang dimaksud proposal penawaran kerjasama ini adalah dalam proposal diterangkan juga bahwa BAZDA akan mencantumkan logo mitra pada materi cetakan sosialisasi atau brosur Ramadhan BAZDA Kota Bekasi dan iklan bersama di media koran. Setelah proposal kerja sama tersebut disetujui maka BAZDA mempersiapkan fundraiser dengan cara memberikan pembekalan kepada Relawan BAZDA Kota Bekasi (REDAKSI) yang nantinya bertugas melakukan interaksi, edukasi dan mengajak pengunjung melakukan donasi. Gerai Ramadhan BAZDA Kota Bekasi dioptimalkan untuk membuka layanan sebulan penuh, selama Ramadhan. Seperti penuturan yang disampaikan oleh Bapak Suherman berikut ini

"Adapun detail pelaksanaan program gerai ramadhan ini diawali dengan pengiriman proposal-proposal penawaran kerjasama, yang dimaksud proposal penawaran kerjasama ini adalah dalam proposal keterangan bahwa BAZDA akan menyantumkan Mitra Logo atau Merek eee.. merek nama rumah makan atau eee.. nama-nama pusat perbelanjaan pada banner-banner yang telah kita sediakan. Setelah kerja sama tersebut disetujui maka BAZDA Kota Bekasi mempersiapkan fundraiser dengan cara memberikan pembekalan kepada Relawan BAZDA Kota Bekasi yang kami singkat dengan REDAKSI, yang nantinya bertugas melakukan interaksi, edukasi dan mengajak pengunjung melakukan donasi. Gerai Ramadhan BAZDA Kota Bekasi dioftimalkan untuk membuka layanan sebulan penuh, selama bulan suci Ramadhan."

Setiap gerai biasanya diisi oleh dua orang fundraiser, yang bertugas untuk memberikan brosur dan menerima Zakat, Infaq Shadaqah (ZIS) langsung di area gerai tersebut. Fundraiser yang bertugas menjaga gerai tersebut selain diwajibkan untuk mengerti mengenai dasardasar hukum tentang ZIS, juga diwajibkan untuk selalu menggunakan pakaian yang rapih dan sopan.

Program gerai ramadhan ini baru pertama kalinya diadakan oleh pihak BAZDA Kota Bekasi pada tahun 2012 ini, dalam program perdana ini BAZDA mentargetkan akan 
membuka lima gerai. Oleh karena itu, BAZDA mengirimkan proposal ke tujuh tempat, yaitu ke Metropolitan Mall (MM), Bekasi Cyber Park (BCP), Giant Harapan Indah, KFC Harapan Indah, Rumah Makan Wulan Sari, Rumah Makan Marga Jaya dan Rumah Makan Pondok Indah Raya. Selanjutnya, dari proposal yang telah dikirim ke tujuh lokasi tersebut ternyata yang diterima hanya di tiga lokasi saja, yaitu di Metropolitan Mall (MM), Rumah Makan Marga Jaya dan Rumah Makan Pondok Indah Raya.

Mengenai biaya untuk membuka satu gerai ramadhan yang dibuka satu bulan penuh selama ramadhan ini membutuhkan dana sebesar 2.200.000,- dengan perincian seperti yang disampaikan oleh bapak Suherman:

"Untuk keperluan dana yang kita perlukan untuk membuka gerai ramadhan selama satu bulan penuh pada bulan ramadhan ini diantaranya untuk keperluan transport fundraiser $(1.500 .000,-)$, seragam fundraiser $(200.000,-)$, mencetak brosur ramadhan $(250.000,-)$, mencetak 2 banner $(150.000,-)$ dan akomodasi $(100.000,-)$. Adapun pendapatan yang dapat dikumpulkan dari program perdana gerai ramadhan BAZDA pada tahun ini adalah sekitar Rp. 6.000.000,- (Enam Juta Rupiah).”

\section{c. Penyebaran Kotak Amal BAZDA}

BAZDA Kota Bekasi juga menyebarkan Kotak Amal ke tempat-tempat potensial dan strategis, seperti Warung Jajan, Mini Market dan Rumah Sakit. Adapun langkah-langkah yang dilakukan dalam menjalankan strategi penyebaran kotak amal adalah dimulai dengan memprediksi potensi dana infaq dan shadaqoh di tempat yang akan dituju, kemudian BAZDA mengirimkan surat resmi tentang permohonan penitipan kotak amal BAZDA, dalam surat tersebut juga tentunya dilampirkan dengan dokumentasi atau foto-foto kegiatan yang telah dilaksanakan. Selanjutnya, setiap pengambilan isi kotak amal oleh staf BAZDA disaksikan oleh mitra tempat penaruhan kotak amal tersebut dan dilakukan dokumentasi untuk selanjutnya disosialisasikan baik melalui surat kabar atau melalui web site BAZDA Kota Bekasi.

Selanjutnya, mengenai anggaran yang harus dikeluarkan untuk program penyebaran kotak amal BAZDA ini ternilai cukup sederhana, untuk penyebaran satu unit kotak amal BAZDA cukup mengeluarkan dana sekitar Rp. 320.000 saja, dengan perinciannya sebagaimana penjelasan dari kepala divisi fundraising, bapak Suherman:

"Anggaran yang kami butuhkan untuk penyebaran kotak amal BAZDA ini ternilai cukup sederhana, untuk penyebaran satu unit kotak amal BAZDA cukup mengeluarkan dana sekitar Rp. 320.000 saja, dengan perinciannya yaitu untuk biaya membuat kotak amal Rp. 200.000,biaya membuat 2 buah stiker untuk ditempel di kotak amal Rp. 20.000,- untuk pengiriman surat izin penitipan kotak amal dan proses akomodasi Rp. 100.000. Adapun pendapatan dari kotak amal ini tidak menentu, biasanya butuh waktu antara 6 bulan sampai 10 bulan lamanya untuk pengambilan hasil kotak amal tersebut. Jumlah yang dapat diraih juga cukup variatif, yaitu antara 1.200.000 sampai 3.500.000.”

\section{d. Kampanye Media}

\section{1). Media Cetak}

Media koran adalah salah satu media iklan yang dipilih oleh tim BAZDA Kota Bekasi dan dinilai cukup ampuh untuk mempromosikan BAZDA, dengan melakukan pendekatan maka BAZDA berhasil menjadikan 
koran Radar Bekasi sebagai media partner BAZDA. Melalui koran radar Bekasi ini BAZDA dapat menyampaikan berbagai macam informasi, diantaranya untuk menyampaikan laporan keuangan dan mensosialisasikan program atau kegiatan yang telah dilakukan oleh BAZDA Kota Bekasi, agar program-program BAZDA dapat diketahui oleh khalayak dan kemudian diharapkan dapat lebih memotivasi masyarakat untuk menyalurkan zakat, infaq dan shadaqohnya ke BAZDA Kota Bekasi. Adapun besaran biaya yang dipelukan BAZDA Kota Bekasi dalam rangka kampanye media melalui koran ini juga terbilang cukup sederhana, untuk setiap syiar BAZDA di koran Radar Bekasi tidak dikenakan biaya periklanan dikarenakan BAZDA memang bukanlah sebuah perusahaan atau lembaga komersial. Hal ini sebagaiman penuturan bapak Suherman:

"Biaya yang kami keluarkan dalam rangka kampanye media melalui koran ini juga terbilang cukup sederhana, untuk setiap syiar BAZDA di koran Radar Bekasi tidak dikenakan tarif biaya periklanan dikarenakan BAZDA memang bukanlah sebuah perusahaan atau lembaga komersial, jadi biasanya BAZDA hanya mengeluarkan budget untuk wawartawan saja ketika meliput, yaitu antara 100.000 sampai dengan 150.000 rupiah.

Media cetak selanjutnya adalah dengan cara penerbitan brosur atau profil BAZDA dan penerbitan buku "Himpunan Peraturan Daerah Kota Bekasi Tentang Pengelolaan Zakat". Buku ini merupakan salah satu media transfer informasi, edukasi dan pedoman zakat, dalam rangka mendukung program kesadaran zakat untuk masyarakat Kota Bekasi.

\section{2). Media Elektronik}

BAZDA Kota Bekasi sebagai organisasi pengelola zakat yang terdaftar resmi oleh Pemerintah Kota Bakasi juga dikenal sebagai organisasi non profit, hal ini dimanfaatkan tim publikasi BAZDA untuk mencari media radio ternama di Kota Bekasi yang siap dijadikan media relasi dan dapat memberikan keringanan biaya untuk beriklan di radio tersebut. BAZDA mengirimkan surat penawaran keringanan biaya tersebut, kemudian setelah mendapat persetujuan dari Radio Elgangga dan Radio Dakta maka kedua radio tersebut telah resmi menjadi media partner BAZDA.

\section{3). Internet}

Seiring dengan kemajuan jaman dan banyaknya masyarakat yang sudah melek teknologi serta semakin meningkatnya konsumsi informasi di dunia maya, maka BAZDA Kota Bekasi pun tidak mau ketinggalan jaman dan membuat website: http:/www.bazdakotabekasi.or.id. yang bertujuan selalu berusaha semaksimal mungkin menyajikan data-data terbaru sebagai media pertanggung jawaban publik meski tak lepas dari kekurangan sanasini. Seperti kutipan wawancara dengan Suherman (14 November 2012) sebagai berikut: 
Yang ketiga, yakni media internet. Seiring dengan kemajuan jaman dan banyaknya masyarakat yang sudah melek terhadap teknologi serta semakin meningkatnya konsumsi informasi di dunia maya, maka BAZDAKota Bekasi pun tidak ingin ketinggalan jaman dan membuat website yang sudah mungkin anda ketahui yang bertujuan selalu berusaha memaksimalkan semaksimal mungkin menyajikan data-data terbaru sebagai media pertanggung jawaban publik meski tak lepas dari kekurangan baik data maupun sebagainya.

\section{e. Strategi Khusus}

Setelah menerapkan empat strategi fundraising utama di atas, BAZDA Kota Bakasi juga memiliki strategi khusus ini bertujuan untuk mempertahankan dan meningkatkan donatur atau, yaitu

\section{Kemudahan Donasi}

Motto utama BAZDA Kota Bekasi dalam hal memberikan kemudahan bagi para donatur atau muzakki ialah "kecepatan dan keramahan adalah penting”. Oleh karena itu, BAZDA Kota Bekasi membuat saluran donasi yang beragam dan mudah dijumpai, yaitu palayanan transaksi langsung dikantor, transfer melalui rekening Bank (Bank JABAR: 10.00.01.005486.4, Bank Mandiri: 125.00000.65151, Bank BRI: 139.01.000.770.303, Bank BNI: 001.6247703, Bank Syariah Mandiri: 0050039197) (Brosur Profil BAZDA Kota Bekasi tahun 2012 : 1). Disamping itu, untuk kemudahan, BAZDA Kota Bekasi memberikan layanan “jemput zakat”. Sebagaimana telah diungkapkan oleh Suherman berikut ini:

"Untuk memberikan kemudahan, BAZDA membuat saluran donasi yang beragam dan mudah dijumpai. Yaitu dengan palayanan transaksi langsung muzakki datang ke kantor, atau juga transfer melalui rekening Bank yang telah kami sampaikan dan kami publikasikan dan juga diadakan layanan jemput zakat."

\section{Layanan Pasca Donasi}

Setiap donatur atau muzakki yang mengamanahkan dana zakat, infaq dan shadaqahnya ke BAZDA Kota Bekasi selalu dilayani dengan keramahan dan dimintakan database berupa nama, alamat dan informasi diri lainnya untuk suatu saat bisa dijadikan sebagai sarana komunikasi timbal balik antara muzakki dengan BAZDA berupa keritik, saran dan keluhan. Atau sekurang-kurangnya agar BAZDA bisa menyampaikan beberapa informasi dan pelaporan yang terkait dengan muzakki.

Biasanya BAZDA Kota Bekasi selain memberikan laporan tahunan juga senantiasa memberikan laporan bulanan, yang setiap awal bulannya difoto copy sekian ratus lembar yang setiap satu bulan sekali dikirim melalui pos atau melalui email dan mengirimkan surat laporan bulanan secara aktual kepada para muzakki dan pihak-pihak yang terkait lainnya. Agar bisa timbul kesepahaman antara Muzakki dengan BAZDA dan juga dengan pelaporan 
ini diharapkan kepercayaan muzakki terhadap pengelolaan BAZDA semakin meningkat. Sebagaimana penuturan yang disampaikan Fuad Noor Yusuf, selaku ketua BAZDA Kota Bekasi:

"Disini kita selalu mengupayakan organisasi kita ini agar selalu transparan dan dapat dipercaya, untuk itu selain kita melakukan laporan pembukuan ahir tahun, kita juga senantiasa membuat laporan bulanan, yang tiap bulannya itu kita copy sekian ratus lembar untuk kemudian kita kirimkan melalui kantor pos ke kelurahan, kecamatan dan dinas se Kota Bekasi. Jadi setiap pemasukan ataupun pengeluaran BAZDA dapat diketahui dengan jelas oleh semua pihak, baik itu muzakki, mustahiq ataupun pihak-pihak lainnya." (Wawancara Pribadi dengan Bapak Fuad Noor Yusuf, selaku Ketua BAZDA Kota Bekasi, 19 November 2012)

Dengan adanya layanan pasca donasi ini diharapkan agar dapat meningkatkan kepercayaan dan kepuasan bagi muzakki. Meningkatkan kepuasan muzakki ini menjadi penting karena kepuasan donatur akan berpengaruh terhadap nilai donasi yang akan diberikan kepada lembaga. Mereka akan memberikan donasinya kepada lembaga secara berulangulang, bahkan menginformasikan kepuasannya terhadap lembaga secara positif kepada orang lain. Salah satu upaya untuk meningkatkan kepuasan muzakki adalah dengan cara memberikan Reward kepada muzakki dan UPZ yang paling taat atau paling maksimal dalam hal menyalurkan zakatnya ke BAZDA Kota Bekasi, dengan cara memberikan Piagam Bekasi Berkah kepada Dinas yang para pegawainya paling taat menunaikan zakat, kemudian dipublikasikan melalui koran. Agar dapat menjadi kebanggan bagi para donatur. Hal ini senada dengan yang disampaikan oleh bapak Zainudin selaku anggota UPZ berikut ini:

“...Menurut saya pemberian Reward itu perlu juga mungkin diadakan, karena ini juga akan bisa menjadi kebanggaan tersendiri buat UPZ yang meraihnya dan juga bisa lebih memotivasi UPZ yang lainya untuk lebih menjalankan tugasnya dengan lebih baik. Kemudian tentunya sebelum mengadakan Reward ini BAZDA ini juga harus sudah lebih baik dan profesional agar pemberian Reward ini merupakan penghargaan yang benar-benar bergengsi." (Wawancara Pribadi dengan Bapak Zainudin, 25 Januari 2013)

\section{Program Aksi}

Mengenai penyaluran dana zakat telah diatur dalam ajaran syari'at Islam, yakni diperuntukan kepada delapan asnaf atau yang lebih dikenal dengan sebutan mustahik. Ketentuan tersebut sesuai dengan firman Allah SWT yang terdapat dalam QS At-Taubah: 60.

Akan tetapi setelah mengacu kepada ketentuan di atas, setiap OPZ yang baik dan profesional tentunya selalu berusaha untuk meningkatkan kualitas layanan (program aksi) kepada warga masyarakat khususnya kaum dhuafa 
dengan berbagai cara dan upaya. Hal Ini senada dengan yang diungkapkan oleh Fuad Noor Yusuf berikut ini:

Di BAZDA Kota Bekasi ini program aksi itu adalah masuk kategori penyaluran dana zakat, oleh karena itu dalam menentukan program aksi disini yang menjadi prioritas kami adalah harus sesuai dengan syari'at. Artinya dalam menentukan program aksi kami senantiasa mengacu kepada ketentuan syari'at islam surah At-Taubah ayat 60 tentang aturan penyaluran zakat kepada delapan asnaf. Akan tetapi setelah mengacu kepada ketentuan di atas, setiap OPZ yang baik dan profesional tentunya selalu berusaha untuk meningkatkan kualitas layanan kepada masyarakat khususnya kaum dhuafa dengan berbagai cara dan upaya.

Dalam hal menentukan penyaluran dana zakat oleh BAZDA Kota Bekasi ataupun Organisasi Pengelola Zakat (OPZ) lainnya harus senantiasa mengacu kepada ketentuan syari'at islam tersebut, oleh karena itu dalam Perda Kota Bekasi tantang Pengelolaan Zakat juga telah mengatur mengenai pendayaguanaan hasil pengumpulan zakat yang tertera dalam Pasal 21 menjelaskan bahwa pendayagunaan dana zakat terbagi kepada dua kategori. Pertama ialah untuk Mustahik dan Kedua ialah untuk Usaha Produktif. (Kantor Kementerian Agama Kota Bekasi : 19.)

Selain itu, organisasi pengelola zakat harus merancang program yang berkualitas dan memiliki nilai keunggulan dalam memerdayakan mustahik. (Direktorat Pemberdayaan Zakat, 2008 : 68) .Program aksi yang berkualitas dalam kemanfaatannya serta dapat dipublikasikan dengan baik itu juga akan mempengaruhi kepercayaan muzakki atau donatur tentang dana yang telah disalurkannya dapat tersalurkan dengan baik dan tentunya itu juga akan mendorong muzakki untuk memberikan sebagian hartanya ke OPZ tersebut.

Sehingga divisi pendistribusian harus selalu bersinergi dengan divisi fundraising dalam menjalankan program aksi, agar program-program dirancang tidak sekedar untuk menghabiskan anggaran atau hanya sekedar asal tersalurkan. Akan tetapi dengan adanya sinergi antara divisi pendistribusian dengan divisi fundraising dapat menghadirkan program yang multimanfaat, yakni dapat menciptakan program yang bermanfaat untuk mustahik juga dapat membentuk citra lembaga yang lebih baik dan menjadi nilai jual terhadap muzakki.

\section{Sumber Dana Untuk Program Fundraising BAZDA Kota Bekasi}

Mengenai sumber dana yang dipergunakan untuk divisi fundraising dalam menjalankan program-programnya tidak terlepas dari dua sumber dana, yaitu dari hak Amilin sebesar $12,5 \%$ dan dari bantuan pemerintah atau APBD yang setiap tahunnya BAZDA mendapatkan APBD sebesar Rp 100.000.000 (Seratus Juta Rupiah). Yang mana kedua sumber dana ini tentunya dipergunakan untuk keperluan operasional BAZDA Kota Bekasi. Hal ini senada dengan yang disampaikan oleh Bapak Suherman: 
"Mengenai sumber dana yang dipergunakan oleh divisi fundraising untuk menjalankan setiap program-programnya tidak terlepas dari dua sumber, yaitu dari hak Amilin sebesar $12,5 \%$ dan dari bantuan pemerintah atau APBD yang setiap tahunnya BAZDA mendapatkan APBD sebesar Rp 100.000.000 (Seratus Juta Rupiah). Yang mana kedua sumber dana ini tentunya dipergunakan untuk keperluan operasional BAZDA Kota Bekasi." (Wawancara Pribadi dengan Bapak Suherman, 23 Januari 2013)

\section{Penutup}

\section{Kesimpulan}

Berdasarkan hasil penelitian yang telah peneliti lakukan serta berdasarkan uraianuraian yang telah penulis kemukakan dalam tiap-tiap bab maka dapat disimpulkan bahwa Strategi fundraising di Badan Amil Zakat Daerah (BAZDA) Kota Bekasi terdiri dari empat strategi inti dan tiga strategi khusus. Tujuh strategi tersebut adalah:

a. Strategi Membentuk Unit Pengumpul Zakat (UPZ)

Strategi pertama yang dilakukan oleh BAZDA Kota Bekasi adalah strategi pembentukan UPZ di tiap-tiap Sekolah, Masjid, Perusahaan dan di kalangan Dinas (Instansi atau SKPD) se Kota Bekasi. Strategi membentuk UPZ ini adalah upaya BAZDA Kota Bekasi untuk dapat mengumpulkan dana Zakat, Infaq dan Shadaqoh (ZIS) di tiap tempat yang menjadi sumber potensial. Dan Hasilnya strategi membentuk UPZ ini adalah strategi yang paling efektif bagi BAZDA Kota Bekasi dalam mengumpulkan dana Zakat, Infaq dan Shadaqoh.

b. Special Event Ramadhan (Gerai Ramadhan)

Pada saat bulan suci ramadhan BAZDA Kota Bekasi mengadakan program Gerai Ramadhan karena sudah sama-sama kita ketahui bahwa bulan ramadhan adalah bulan zakat dan shadaqoh karena selain pada bulan ini umat islam diwajibkan untuk menunaikan zakat fitrah juga pada bulan ini umat islam banyak mengeluarkan shadaqoh. Untuk itu BAZDA Kota Bekasi juga tidak mau menyia-nyiakan moment bulan ramadhan ini untuk melakukan strategi jamput bola yakni dengan membuka Gerai Ramadhan di tempat-tempat yang banyak dikunjungi seperti di pusat pembelanjaan dan restauran atau rumah makan populer di Kota Bekasi.

c. Penyebaran Kotak Amal BAZDA

Melihat besarnya potensi masyarakat umum yang ingin memberikan infaq dan shadaqoh dengan nominal yang tidak begitu besar namun memiliki intensitas dan frekuensi atau jumlah muzakki yang sangat banyak serta untuk dapat memberikan kemudahan bagi masyarakat yang ingin berbagi dari hartanya, maka BAZDA Kota Bekasi menyebarkan Kotak Amal ke tempat-tempat potensial dan strategis, seperti Warung Jajan, Mini Market dan Rumah Sakit.

d. Kampanye Media

Sosialisasi secara meluas juga merupakan sebuah strategi untuk lebih mengembangkan kapasitas lembaga, semakin dikenal suatu lembaga maka 
tentunya akan memungkinkan semakin banyak donatur atau muzakki yang akan memberikan sebagian dananya kepada lembaga tersebut.

e. Kemudahan Donasi

Motto utama BAZDA Kota Bekasi dalam hal memberikan kemudahan bagi para donatur atau muzakki untuk menyalurkan sebagian hartanya ialah "kecepatan dan keramahan adalah penting".

f. Layanan Pasca Donasi

Biasanya BAZDA Kota Bekasi selain memberikan laporan tahunan juga senantiasa memberikan laporan bulanan, yang setiap awal bulannya difoto copy sekian ratus lembar yang setiap satu bulan sekali dikirim melalui pos atau melalui email dan mengirimkan surat laporan bulanan secara aktual kepada para muzakki dan pihak-pihak yang terkait lainnya. Agar bisa timbul kesepahaman antara Muzakki dengan BAZDA dan juga dengan pelaporan ini diharapkan kepercayaan muzakki terhadap pengelolaan BAZDA semakin meningkat.

g. Program Aksi

Dalam hal menentukan penyaluran dana zakat oleh BAZDA Kota Bekasi ataupun Organisasi Pengelola Zakat (OPZ) lainnya harus senantiasa mengacu kepada ketentuan syari'at Islam tersebut, oleh karena itu dalam Perda Kota Bekasi tantang Pengelolaan Zakat juga telah mengatur mengenai pendayaguanaan hasil pengumpulan zakat yang tertera dalam Pasal 21 menjelaskan bahwa pendayagunaan dana zakat terbagi kepada dua kategori. Pertama ialah untuk Mustahik dan Kedua ialah untuk Usaha Produktif.

Selain itu, organisasi pengelola zakat harus merancang program yang berkualitas dan memiliki nilai keunggulan dalam memerdayakan mustahik. Program aksi yang berkualitas dalam kemanfaatannya serta dapat dipublikasikan dengan baik itu juga akan mempengaruhi kepercayaan muzakki atau donatur tentang dana yang telah disalurkannya dapat tersalurkan dengan baik dan tentunya itu juga akan mendorong muzakki untuk memberikan sebagian hartanya ke OPZ tersebut.

\section{Saran}

Berdasarkan hasil penelitian yang diperoleh, maka dengan ini peneliti mengemukakan beberapa saran yang diharapkan dapat meningkatkan serta memotivasi divisi fundraising Badan Amil Zakat Daerah (BAZDA) Kota Bekasi. Saran-saran yang dapat dikemukakan antara lain:

a. Strategi fundraising sangat diperlukan bagi lembaga-lembaga atau organisasi nirlaba, karena strategi fundraising juga tidak hanya diartikan sebagai divisi pengumpul dana semata, tetapi juga terhadap bentuk partisipasi dan kepedulian dari setiap elemen masyarakat yang dapat dimanfaatkan untuk keperluan organisasidan mempertahankan eksistensi OPZ. Untuk dapat menambah jumlah donasi, maka ada dua cara yang dapat ditempuh, 
yaitu menambah donasi dari setiap donatur atau menambah jumlah donatur pada saat setiap donatur mendonasikan dana yang tetap sama. Diantara kedua pilihan tersebut, maka menambah donatur adalah cara yang relatif lebih mudah dari pada menaikan jumlah donasi dari setiap donatur. Oleh karena itu penulis menyarankan sebaiknya BAZDA Kota Bekasi bisa lebih meningkatkan proses fundraising atau penggalangan dana tidak hanya terfokus kepada PNS saja yang hanya berjumlah 14.000 orang, melainkan harus lebih meluas sampai kepada semua kalangan masyarakat kota Bekasi yang berprofesi lainnya. Seperti para pengusaha, karyawan swasta dan lain-lain yang tentu jumlahnya jauh lebih banyak.

b. Memperhatikan hasil wawancara atau saran dari salah seorang anggota UPZ, maka penulis menyarankan agar BAZDA Kota Bekasi memberikan Reward kepada UPZ yang paling aktif dan paling maksimal dalam mengumpulkan zakat. Dengan cara memberikan Piagam Bekasi Berkah kepada Dinas yang para pegawainya paling taat menunaikan zakat, kemudian dipublikasikan melalui Koran. Agar dapat menjadi kebanggan bagi para donatur. 


\section{Bibliografi}

\section{Buku}

David, Fred., Manajemen Strategi Konsef. Jakarta: PT. Prehalindo, 1998.

Direktorat Jenderal Bimbingan Masyarakat Islam Direktorat Pemberdayaan Zakat, Fikih Zakat. Jakarta: Departemen Agama RI, 2008.

Direktorat Jenderal Bimbingan Masyarakat Islam Direktorat Pemberdayaan Zakat, Panduan Pengembangan Usaha Bagi Mustahiq. Jakarta: Departemen Agama RI, 2008.

Direktorat Jenderal Bimbingan Masyarakat Islam Direktorat Pemberdayaan Zakat, Pedoman Zakat 9 Seri. Jakarta: Departemen Agama RI, 2008.

Hafidhuddin, Didin dan Juwaeni, Ahmad, Membangun Peradaban Zakat. Jakarta : IMZ, 2006.

Kantor Kementerian Agama Kota Bekasi, Himpunan Peraturan Daerah Kota Bekasi Tentang Pengelolaan Zakat. Bekasi: BAZDA Kota Bekasi, 2010.

Moleong, Leky J, Metodologi Penelitian Kualitatif. Bandung : PT Remaja Rosdakarya, 2003.

Muhammad, Taufik Ridlo, Zakat Profesi dan Perusahaan. Jakarta: IMZ, 2007.

Panitia Istilah Manajemen Lembaga PPM. Kamus Istilah Manajemen. Jakarta : Balai Aksara, 1983.

Poerwandadi, Kristi E. Pendekatan Kualitatif dalam Penelitian Psikologi. Jakarta: LPSP3, 1998.

Purwanto, April, Manajemen Fundraising Bagi Organisasi Pengelola Zakat. Yogyakarta: Teras, 2009.

Rafi'udin dan Abdul Jalil, Maman, Prinsip dan Strategi Dakwah. Bandung: Pustaka Setia, 1997.

Sani, Anwar, Jurus Menghimpun Pulus. Jakarta: PT Gramedia Pustaka Utama, 2010.

Steiner, George dan Miller, John. Manajemen Strategic. Jakarta: Erlangga, 2000.

Sudewo, Erie. Manajemen ZIS. Jakarta: IMZ, 2012.

Sugiyono. Memahami Penelitian Kualitatif. Bandung: CV. Alfabeta, 2009.

Uchyana, Onong. Ilmu Komunikasi Teori dan Praktek. Bandung: PT.Remaja Rosdakarya, 1992.

Warson Munawwir, Ahmad. Al-Munawwir Kamus Arab-Indonesia. Surabaya: Pustaka Progressif, 1997.

Young, Joyce. dkk. Menggalang Dana Untuk Organisasi Nirlaba. Jakarta: PT. Ina Publikatama, 2007.

\section{Internet}

Pira. "Pelatihan.Perencanaan.Strategis.Fundraising." artikel diakses pada 6 Desember 2011 dari http://stit-attaqwa.blogspot.com/2011/07/strategi-fundrising.html. 